\title{
NEOCLASSICAL REALISM, THE STATE AND FOREIGN POLICY
}

Steven E. Lobell, Norrin M. Ripsman y Jeffrey Taliaferro, eds. Cambridge: Cambridge University Press, 2009, 324 páginas.

Que la trayectoria intelectual del realismo en el campo de las Relaciones Internacionales constituye en sí mismo un objeto de estudio de la disciplina es algo poco cuestionado. Pocas tradiciones de especulación sobre la política mundial han arrojado tantos autores, miradas, conceptos y teorías como el realismo. El libro Neoclassical Realism, the State and Foreign Policy editado por Lobell, Ripsman y Taliaferro representa un aporte más a un largo recorrido intelectual que a pesar de continuar obsesionado con la lucha por el poder no deja de ofrecer nuevas miradas para entender su lógica. En el realismo, la aburrida repetición de sus problemáticas se ve ampliamente compensada por la estimulante innovación de sus abordajes. Neoclassical Realism, the State and Foreign Policy viene a consolidar casi diez años de especulación en torno a la tercera gran movida teórica del realismo, el 'Realismo Neoclásico', según el concepto acuñado por Gideon Rose en $1998 .{ }^{1}$

La primera ola realista tuvo que ver con la lucha por el poder entre individuos y grupos, siendo el estado el grupo más relevante en los asuntos mundiales. Esta primera ola enfatizó la naturaleza humana conflictiva, las dinámicas de acumulación de poder por parte de los estados y los dilemas que los estadistas deben enfrentar para proteger la flor rara del interés nacional en un mundo de comportamientos egoistas que llevan a la Realpolitik. La segunda ola sacó a la naturaleza humana y al estado de la explicación acerca del conflicto y enfatizó la estructura de un juego cuyos jugadores no pudieron elegir: la ausencia de gobierno mundial, la similitud entre los estados y la distribución desigual del poder. Esta segunda ola construyó un realismo estructural que afirmó que el comportamiento internacional de los estados no se explica a partir de los asuntos domésticos sino de las características del ambiente internacional, el cual provee restricciones y oportunidades. El debate no se centró en la naturaleza del estado sino en la naturaleza del sistema in- 
ternacional y si éste proveía incentivos para políticas expansionistas y de acumulación de poder (realismo ofensivo) o para políticas defensivas y de maximización de seguridad (realismo defensivo). Frente a una primera ola de reflexiones filosóficas y políticas sobre los dilemas del poder, la segunda ola trajo un conjunto de teorías que con abstracción y parsimonia establecieron comportamientos internacionales a partir de condiciones sistémicas. La profundidad y sofisticación del realismo clásico fue sacrificado en el altar positivista del realismo estructural.

El realismo neoclásico abre de nuevo la oportunidad para retomar la contingencia del primer realismo sin declararse en contra de la perspectiva estructural. Comienza su abordaje del mismo modo que el realismo estructural, esto es que el ambiente internacional ejerce un rol central en configurar las preferencias de los estados. Pero luego toma distancia al afirmar que el estado no es necesariamente un actor racional y untario que actúa como una correa de transmisión entre los incentivos del sistema y las políticas llevadas a cabo por el gobierno. Así, la condición del sistema internacional es central para entender la inserción de los estados, pero entre la mirada del sistema internacional llevada a cabo por los funcionarios en el poder y las decisiones tomadas existe un cojunto de variables intervinientes que ejercen singular influencia en el proceso de toma de decisiones. De este modo, el realismo neoclásico articula variables del nivel internacional con variables del nivel doméstico para presentar explicaciones singulares. Algunas de las preguntas que plantean los autores del libro son las siguientes: ¿Cómo evalúan los funcionarios a cargo de la política exterior las restricciones y amenazas del sistema internacional? ¿Por qué a veces el poder ejecutivo no puede actuar a partir de la información que posee del sistema internacional y por lo tanto falla en adaptarse a la dinámica que el sistema le impone? ¿Qué rol ejercen los actores domésticos en restringir las opciones de política exterior? ¿Qué pasa cuando una coalición política no comparte una misma evaluación de las amenazas del ambiente internacional internacional? En definitiva, ¿por qué los estados no se comportan de acuerdo a lo que cabría esperar desde el realismo estructural?

Neoclassical Realism, the State and Foreign Policy persigue tres ob- 
jetivos centrales. Primero, busca refinar el enfoque del realismo neoclásico y presentarlo no como una teoría sino como un conjunto de teorías. Segundo, busca dialogar con el realismo clásico y el realismo estructural y también con otras teorías internacionales, ofreciendo una via media entre explicaciones sistémicas materiales y explicaciones domésticas ideacionistas. Tercero, establece un conjunto de conceptos y categorias para llenar un viejo vacío en la reflexión realista y construir una visión más acabada acerca del estado como agente de las relaciones internacionales. En particular, los distintos autores del libro trabajan sobre al menos cinco variables de carácter doméstico que intervienen entre la realidad del ambiente internacional y las decisiones finalmente adoptadas por los gobiernos.

La primera variable tiene que ver con las percepciones de los líderes. En las percepciones influyen cuestiones como la ideología, el nacionalismo o la religión. Se trata de elementos que restan objetividad al análisis del ambiente internacional y por lo tanto que aumentan los costos para el estado en cuestión. Así, por ejemplo, una particular combinación de aspectos religiosos e ideológicos configuró la política exterior de George Bush y lo llevó a embarcarse en una guerra (contra Irak) que nunca tendría que haber aparecido si hubiera mirado el mundo con lentes realistas.

La segunda variable tiene que ver con el grado de cohesión de las elites y la capacidad para articular una visión y una estrategia general compartida por todos. Un estado con elites polarizadas difícilmente pueda reaccionar a los incentivos y restricciones que ofrece el ambiente internacional.

La tercera variable se relaciona con la influencia de los actores domésticos, como las empresas, los partidos políticos, los sindicados o los medios de comunicación. El realismo neoclásico se pregunta bajo qué condiciones internacionales y domésticas estos actores domésticos tendrán mas o menos importancia en la configuración de políticas exteriores.

La cuarta variable consiste en la capacidad extractiva que tiene un estado para dirigir recursos de un sector (el económico) a otro (el militar). Incluso asumiendo que el estado hace una lectura correcta del ambiente 
internacional, el realismo neoclásico se concentra en definir si el estado en cuestión dispone de los recursos y de la capacidad para administrarlos en función de sus objetivos de política exterior y de seguridad.

La quinta variable, finalmente, tiene que ver con la capacidad de movilización que posee el estado en términos de opinión pública, identidades políticas o circunstancias en donde el estado cuente con el apoyo de la población para llevar adelante determinadas movidas de política exterior.

A partir de estas variables, el realismo neoclásico no presenta una teoría de patrones sistémicos como lo hace el realismo estructural. Más bien, presenta una teoría que da cuenta de las variaciones dentro de un estado (en el tiempo) o entre estados (en el espacio) a partir de circunstancias internacionales similares. El punto de partida es el conjunto de restricciones y oportunidades que plantea el ambiente internacional. Los ejecutivos deben evaluar la amenaza, elaborar un ajuste estratégico y ponerlo en marcha. La observación central del realismo neoclásico, sin embargo, es que los estados no siempre gozan de autonomía para llevar adelante estas tres operaciones sin la intervención de factores de política doméstica o de ideas que configuran un conjunto de salidas distintas a las que se derivan de una lectura realista del entorno global. Así, un estado con (a) una percepción correcta de las fuerzas materiales que operan a nivel global y regional, (b) con una elite cohesionada en torno a una definición compartida de amenazas, (c) con poder suficiente como para poner límite a las presiones de los actores domésticos, (d) con amplia capacidad extractiva y (e) con amplia capacidad de movilización de recursos materiales y simbólicos tendrá muchas más posibilidades de comportarse de acuerdo a los incentivos y restricciones que presenta el ambiente internacional.

Aunque cada capítulo está escrito por un autor distinto, el libro está articulado en torno a un conjunto de preguntas de investigación, ofrece una introducción teórica muy sólida y termina con una conclusión que compara los hallazgos de cada capítulo, ofrece un conjunto de caminos para seguir investigando y dialoga a su vez con otras explicaciones de la política exterior e internacional. Se trata de un libro que hace dos 
aportes centrales. Por un lado, sistematiza los desarrollos teóricos del realismo neoclásico y presenta un conjunto sofisticado de hipótesis de investigación. Por otro lado, presenta estudios de casos en donde el realismo neoclásico entra en acción, ofreciendo explicaciones atractivas y con capacidad para tender puentes entre abordajes materiales y sociales. De esta forma, el libro consolida una perpectiva que logra tres cosas. Primero, reintroduce el análisis de política exterior en los manuales realistas, algo que había quedado en un segundo lugar desde el taboo reduccionista introducido por Kenneth Waltz. Segundo, ofrece un camino medio para combinar variables materiales con variables sociales y por lo tanto abre nuevas oportunidades para elaborar explicaciones que puedan ser contrastadas con el constructivismo. Tercero, presenta un adelanto significativo en el análisis y comprensión del estado, las dinámicas de la política doméstica y las estructuras materiales e institucionales que favorecen o no comportamientos realistas. La lección general del libro quizás pueda ser resumida del siguiente modo: un estado realista no nace, se hace. Neoclassical Realism, the State and Foreign Policy introduce un aporte significativo para entender cómo y bajo qué circunstancias un estado se hace realista o de lo contrario, como sostienen sus autores, sufre las consecuencias.

Federico Merke

${ }^{1}$ Giden Rose, "Neoclassical Realism and Theories of Foreign Policy," World Politics, 51, no. 1 (October 1998), pp. 144-177. 